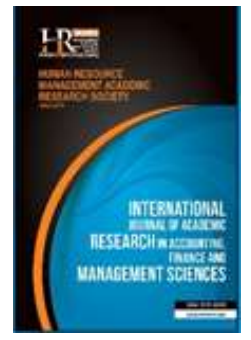

International Journal of Academic Research in Accounting, Finance and Management Sciences

Vol. 9, No.4, October 2019, pp. 43-48

E-ISSN: 2225-8329, P-ISSN: 2308-0337

(C) 2019 HRMARS

www.hrmars.com

To cite this article: Anghelache, C., Anghel, M.-G., lacob, S.V., Bîrsan, O. (2019). Analysis of the Effect of Acceleration

in Dynamic Models, International Journal of Academic Research in Accounting, Finance and Management Sciences

9(4): $43-48$

http://dx.doi.org/10.6007/IJARAFMS/v9-i4/6632 (DOI: 10.6007/IJARAFMS/v9-i4/6632)

\title{
Analysis of the Effect of Acceleration in Dynamic Models
}

\author{
Constantin Anghelache ${ }^{1}$, Madalina-Gabriela Anghel ${ }^{2}$, \\ Stefan Virgil lacob ${ }^{3}$, Oana Bîrsan ${ }^{4}$ \\ ${ }^{1}$ Bucharest University of Economic Studies/„Artifex” University of Bucharest, Romania, ${ }^{1}$ E-mail: actincon@yahoo.com \\ 2,3, Artifex" University of Bucharest, Romania, \\ ${ }^{2}$ E-mail: madalinagabriela_anghel@yahoo.com, ${ }^{3}$ E-mail: stefaniacob79@yahoo.com \\ ${ }^{4}$ Bucharest University of Economic Studies, Romania, ${ }^{4} E$-mail: oana.vilcu@fiscont.com.ro
}

\begin{abstract}
In the article entitled "Analysis of the effect of acceleration in the Sunday models", the authors focused their attention on the dynamic models due to the possibilities offered by them to make precise analyzes on the evolution of a dependent variable due to the influences that the independent variables have on them. Analyzing the nature of these influences, we found that there is the prospect of accelerated evolution of these variables. At the macroeconomic level, in order to realize the forecasts of certain economic phenomena that influence the evolutions of the different states, we can use for a performance analysis the model of the accelerator without cycle, which due to its properties can give a realistic perspective on the tendency of the system evolution. Starting from the use of the term cyclicality, which characterizes the evolution of the various economic phenomena in one way or another depending on the various elements that determine this evolution, the authors will use it in this sense, in analyzing the accelerator of the dynamic models. Following this construction, the harmonized cycle accelerator model will take into account the fact that there must be such a correlation of the acceleration application in one direction or another. For example, if we take into account the problem of diminishing consumption in the national economy, we consider that a measure of negative acceleration must be taken in order to reduce it. At the same time, an increase in investments is needed, which implies the use of a harmonized cycle accelerator model, given that the measure aims at both an increase and a decrease, which is constantly harmonized. In the economy, we encounter cases in which the evolutions have a very high intensity in a relatively short period of time, thus accelerating, resulting in obtaining revenues well above the equilibrium aimed at maintaining macrostability, cases in which we will approach the accelerator model with explosive cycle. Considering the explosion, the accelerator is the one that leads to a special jump, evolving in its direction in both the positive and negative directions. The article also addresses other important issues such as the significance of these models, which in the authors' opinion should be considered as dynamic systems and which used in forecast models can manifest their influence in the right sense.
\end{abstract}

Key words

Accelerator, Dynamic Models, Speed, Revenue, Cycle, Evolution

Received: 05 Nov 2019 (C) The Authors 2019

Revised: 12 Nov 2019 Published by Human Resource Management Academic Research Society (www.hrmars.com)

Accepted: 02 Dec 2019 This article is published under the Creative Commons Attribution (CC BY 4.0) license. Anyone may reproduce, distribute, translate and create derivative works of this article (for both commercial and non-commercial purposes), subject to full attribution to the original publication and authors. The full terms of this license may be seen at: http://creativecommons.org/licences/by/4.0/legalcode

\section{Introduction}

In the article, the accelerator of dynamic models, the authors sought to study economic models from a static and dynamic point of view. From the point of view of the static analysis, it has been stated that it is based on the existing data series at a given time, depending on which, through the parameters (calculated coefficients), an increase of the resultant variable that we consider is ensured. 
Dynamic models are based on an accelerator in the sense that there are factorial or managerial possibilities to influence certain factorial variables to evolve in the desired direction in order to obtain the expected results. In this sense, for example, the model of the National Income, which is based on true cycles and which in the following relations, must also evolve on the basis of an accelerator, i.e. variables that determine the acceleration of the growth of the variable considered.

From the point of view of the accelerator that we mentioned the authors studied the model of the accelerator without cycle, summarizing in this way that certain factors need to be influenced at a given time and not cyclical because the equilibrium state cannot be produced, which translated in other terms is the element of macrostability. There are also models that consider the accelerator with a damped cycle, the authors presenting a short study that shows that this is a concrete situation that is required when an increase or decrease effect must be clearly offset by a model with reverse evolution, meaning the term depreciated means the accelerator that maintains the economic balance.

In the published article there are also references to the constant cycle accelerator, which refers to the fact that based on the future estimation parameters of the evolution of the indicator or the resultant statistical variable, it will influence under the same approximate conditions all the factors that led to the equilibrium state, so that the evolution be constant.

There are also cases in which the studies carried out reveal the conclusion that a measure undertaking would be necessary, in particular to stimulate the acceleration of the influence of certain factors in order to produce either balance or a more substantial increase in the resultant variable considered. In this sense, we can identify that by aggressively increasing labor productivity as a result of introducing into production the latest achievements of science, technique, innovation and innovation, there is an increase of the respective factor and this will have an influence on the growth of the resultant variable. References were made in the article and to the explosion that is produced by the company of measures that stimulate the more accentuated evolution of the factor that interest us and last but not least, some appraisals were made regarding the significance of the dynamic models used.

The article makes theoretical references to clarify the terms used that it consecrates using short examples that give the idea of accelerator of dynamic models or the use of accelerator in the considered dynamic models.

\section{Literature review}

Anghelache et al. (2019a) analyzes some econometric concepts and models for analyzing macroeconomic performance. Anghelache et al. (2019b) analyzes the main indicators of national wealth that have an effect on macroeconomic performance. Anghelache and Anghel (2019a), addresses in their work theoretical and practical aspects regarding economic statistics. Anghelache and Anghel (2019b), it addresses the problems of economic modeling. Anghelache et al. (2019c) analyzes models used in dynamic series analysis. Bollerslev and Wooldridge (1992) are concerned with estimating the probabilities and interference of dynamic models that are time-varying. Hansen et al. (2008) analyzes in their work the expost variation of equity prices in the presence of noise. lacob (2019) analyzes the coefficient of capital, the coefficient of acceleration and the productivity of investments, correlating them with the economic amplifier. Linton (2016) is concerned in his work with probabilistic statistical-econometric analyzes. In this article addresses problems related to non-parametric estimation and analyzes the degree of sensitivity of the predicted deficiency (Scaillet, 2004). Stambaugh and Yuan (2017) it raises the problem of factors not taken into account that influence the various economic phenomena.

\section{Methodology, data, discussions, results}

If in a model of national income there must be true cycles, then it is necessary to introduce additional relations such as accelerator. This implies a relationship between the level of investments and the change in national income. Suppose the investment is a constant, $K_{t}$ plus a constant proportion, $\alpha$, of the modification of the income between the two previous years. The mathematical relation can be written:

$$
I_{t+2}=I_{0}+\alpha\left(Y_{t+1}-Y_{t}\right)
$$


Constant, $\alpha$, it is called accelerator, because it reflects the assumption that an increase in income is accelerated by stimulating investments. This stimulation is generally assumed due to the fact that an increase in production requires at least a proportional increase in the total stock of equipment needed to produce this result. If the production of this equipment has been sufficient in the past to replace a given stock as it has worn out, increasing the stock requires a temporary increase in the production of equipment proportionately larger than the growth of the final product. Therefore, suppose that 1 machine produces 10 products and lasts 5 years. If the annual production of these products is 100 , there will be 10 cars, of which 2 will be replaced every year. Suppose now that the production increases to 120 . In the year of growth 12 cars will be required, so that the production of cars must jump from 2 to $4 ; 2$ for replacement and another two to bring the total number up to 12 . A $20 \%$ increase in production therefore requires a 100 percent increase in car production.

To return now to the dynamic model, suppose that there is a linear consumption function before, so that the consumption is constant, $C_{0}$, plus a fixed proportion, $\beta$, from the national income of the previous year. Constant, $\beta$, is the tendency to consume. In this context we formulate the relationship:

$$
C_{t+2}=C_{0}+\beta Y_{t+1}
$$

From the identity of the economy-investments we obtain a differential equation of the second order, of the form:

$$
Y_{t+2}=C_{t+2}+I_{t+2}=C_{0}+\beta Y_{t+1}+I_{0}+\alpha\left(Y_{t+1}-Y_{t}\right)
$$

- Analysis of the accelerator model without a cycle

The properties of this system can be illustrated by mathematical examples. In these examples, we will assume $C_{0}=800, I_{0}=200$ and $\beta=0.8$, so that the equilibrium value is the same each time, equal to $1000 /(1-0.8)=5000$. Tables 1 through 5 show the rate of national income with accelerator, $\alpha$, equal with $0.1 ; 0.5 ; 1.0 ; 1.1$ and 2.0 . It is found that the influence of a small accelerator is to accelerate the movement towards equilibrium. Thus, the accelerator comes into play in year 2 , when it produces an investment component equal to the increase in income between years 0 and 1 (200, from 4000 to 4200 ) multiplied by the accelerator, $0.1: 200 \times 0.1=20$. If the acceleration had not occurred, the national income would have been 4360 in year 2; but due to the investment produced by the increase of the incomes, the increase of the incomes in the next period is greater. That is, when revenues grow, the accelerator gives it extra speed. Similarly, when revenues fall, the accelerator also gives it an additional downward speed and makes it drop faster. In Table 1 this additional speed is sufficiently low and achieves acceleration towards equilibrium.

$$
\text { Table 1. The model of the accelerator with } \alpha=0,1 \text { and } \beta=0,8
$$

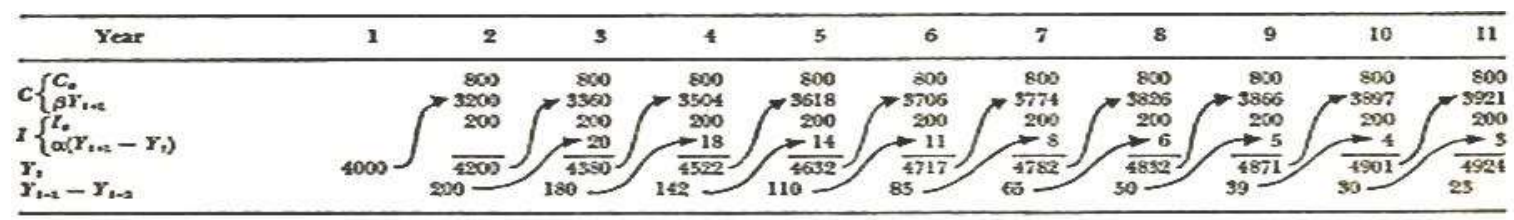

\section{- Analysis of the accelerator model with damped cycle}

If the accelerator itself is slightly larger, the influence will be sufficiently large for the income to grow beyond the equilibrium value of 5000 . Fulfilling this, the consumption function in the equation $\left(\beta Y_{t+1}\right)$ it works and the revenue drops again by establishing a cycle. If the accelerator is smaller than the unit value, this cycle will be amortized, ie successive fluctuations will make smaller and smaller changes, until the

\begin{tabular}{|c|c|c|c|c|c|c|c|c|c|c|c|c|c|}
\hline Year & 0 & I & 2 & 3 & 4 & 5 & 6 & 7 & 8 & 9 & 10 & It & 12 \\
\hline$c\left\{c_{0}\right.$ & & 800 & 800 & 800 & 800 & 800 & 800 & 800 & 800 & Boo & 800 & 800 & 800 \\
\hline$C\left\{g Y_{t-2}\right.$ & & 3250 & 3360 & 5568 & 5758 & 3900 & 3993 & 4040 & 4056 & 4053 & SOHI & 4027 & 4015 \\
\hline$\left\{\begin{array}{l}I_{s} \\
\text { s. }\end{array}\right.$ & & 200 & 200 & 2000 & 200 & 2000 & 200 & 200 & 2000 & 200 & 200 & 200 & 200 \\
\hline${ }^{1}\left\{\alpha\left(Y_{n+4}-Y_{i}\right)\right.$ & & & 100 & 190 & 119 & 89 & 57 & 30 & 10 & -2 & -7 & -8 & -7 \\
\hline $\begin{array}{l}Y_{n} \\
Y_{s-2}-Y_{20}\end{array}$ & 4000 & 200 & 200 & 258 & $17 \overline{4877}$ & 114 & $\overline{59}$ & 20 & $\begin{array}{l}5066 \\
-4\end{array}$ & $\begin{array}{c}\overline{505 t} \\
-15\end{array}$ & ${ }_{-17}^{5048}$ & $\begin{array}{c}3019 \\
-15\end{array}$ & -11 \\
\hline
\end{tabular}
swings eventually become imperceptible. This is evident in Table 2, where the acceleration is 0.5 .

Table 2. The model of the accelerator with ${ }^{\alpha=0,5}$ and $\beta=0,8$ 
It will be seen that by year 6 the speed of the accelerator is sufficient to bring the national income above the equilibrium value of 5000 , up to 5070 in year 7 . In year 8 , the force of the consumption function is strong enough to overcome the weak accelerator, and revenue is starting to fall. Until the year 15 , the balance is practically reached, and the fluctuations become very small.

- Analysis of the accelerator model with the constant cycle In the variant in table 3 , we find that the accelerator is equal to 1.0 .

Table 3. The model of the accelerator with ${ }^{\alpha=1,0}$ and $\beta=0,8$

\begin{tabular}{|c|c|c|c|c|c|c|c|c|c|c|c|c|c|c|c|c|}
\hline Year & 0 & 1 & 2 & 3 & 4 & 5 & 6 & 7 & 8 & 9 & 10 & HI & 12 & 13 & 14 & 15 \\
\hline$c^{c_{0}}$ & & 800 & 800 & 880 & 800 & 800 & 800 & 800 & 800 & 800 & 800 & 800 & 800 & 800 & 800 & 80 \\
\hline$\left\{\beta Y_{t=t}\right.$ & & $\$ 2000$ & 3560 & 3648 & 4006 & 4363 & 4647 & 4802 & 4796 & 4631 & 4340 & 3981 & 3006 & 3346 & 3197 & 5200 \\
\hline$\left\{I_{0}\right.$ & & 200 & 200 & 200 & 200 & 200 & 200 & 200 & 200 & 200 & 200 & 200 & 200 & 200 & 200 & 200 \\
\hline$\left\{a\left(Y_{t-2}-Y_{t-2}\right)\right.$ & & & 200 & 360 & 448 & 496 & 365 & 193 & -7 & -206 & -364 & -449 & -44 & -350 & -185 & +15 \\
\hline & 4000 & 4200 & $\overline{5560}$ & $\overline{5008}$ & $\overline{5454}$ & $\overline{5809}$ & 6002 & 5995 & $\overline{5789}$ & $\overline{5425}$ & 4976 & 45332 & 4182 & 3996 & 4011 & 4224 \\
\hline$Y_{2,2}-Y_{t a}$ & & 2003 & -960 & +448 & $+446+$ & $355+$ & +193 & $-7 \cdot-$ & 87 & $-\$ 64$ & 449 & -444 & -300 & -186 & +15 & +213 \\
\hline
\end{tabular}

Here, the speed of the accelerator in increasing or decreasing revenue occurs when the revenues fall, being so high that a perpetual cycle is established. The accelerator influences the revenue so fast that the equilibrium point is exceeded until year 3. The consumption function leads to the level of 6000 in year 6 , and the income begins to fall again. The accelerator ensures growth beyond equilibrium again in year 10, but reaches a minimum of about 4,000 in year 13 . Rounding determines the figures in the table to be slightly inaccurate. It is clear that revenues will continue to fluctuate between 4000 and 6000 endlessly.

- Analysis of the accelerator model with the explosive cycle

If the accelerator is now greater than 1.0, the explosive cycles will be configured, each increase being greater than the previous one. This is shown in Table 4, where the accelerator is 1.1.

Table 4. The model of the accelerator with ${ }^{\alpha=1,1}$ and $\beta=0,8$

\begin{tabular}{|c|c|c|c|c|c|c|c|c|c|c|c|c|c|c|c|c|}
\hline Yeas & 0 & 1 & 2 & 3 & 4 & 5 & 6 & 7 & 8 & 9 & 10 & 11 & 12 & 13 & 14 & 15 \\
\hline $\int c_{0}$ & & 800 & 890 & 800 & 800 & 800 & 800 & 800 & 800 & 800 & 800 & 800 & 800 & 800 & 800 & 800 \\
\hline$C\left\{\begin{array}{l}\beta Y_{t-4} \\
\end{array}\right.$ & & $\$ 200$ & $\$ 960$ & 3664 & 4006 & 4494 & 4887 & 5104 & 3144 & 4969 & 4562 & 4050 & 3456 & 2911 & 2550 & 2404 \\
\hline$\pi_{0}$ & & 2000 & 200 & 200 & 200 & 200 & 200 & 200 & 200 & 200 & 200 & 200 & 200 & 200 & 200 & 200 \\
\hline$\left\{a\left(Y_{2-1}-Y_{t-2}\right)\right.$ & & & 220 & 418 & 352 & 590 & 313 & 326 & 55 & -232 & -519 & -730 & -817 & -749 & -525 & -173 \\
\hline & 4000 & 4900 & $\overline{450}$ & $\overline{5002}$ & $\overline{5618}$ & $\overline{a s t}$ & $\overline{6890}$ & $\overline{6450}$ & $\overline{6199}$ & $\overline{5727}$ & $\overline{5063}$ & $\overline{4520}$ & $\overline{3539}$ & $\overline{3162}$ & $\overline{3006}$ & $\overline{3231}$ \\
\hline$y_{t-1}-y_{t-a}$ & & 290 & 380 & 502 & 585 & 466 & 296 & $50 \quad-9$ & $11-4$ & $72-6$ & 64 & $45-6$ & $581-$ & $4 \pi-$ & 157 & +205 \\
\hline
\end{tabular}

The accelerator brings revenues well beyond equilibrium to a maximum of about 6430 , then drops it to a minimum of about 3005, well below the initial value of 4000 .

- Maximizing acceleration (explosion)

Finally, if the accelerator is larger, the acceleration effect completely exceeds the effect consumption function, and the income always evolves in the accelerator direction, although it may eventually record a declining pace. The consumer function is never strong enough to reverse direction in a cycle, not even an explosive cycle. This is illustrated in Table 5, where the accelerator is 2.0.

Table 5. The model of the accelerator with ${ }^{\alpha=2,0}$ and $\beta=0,8$

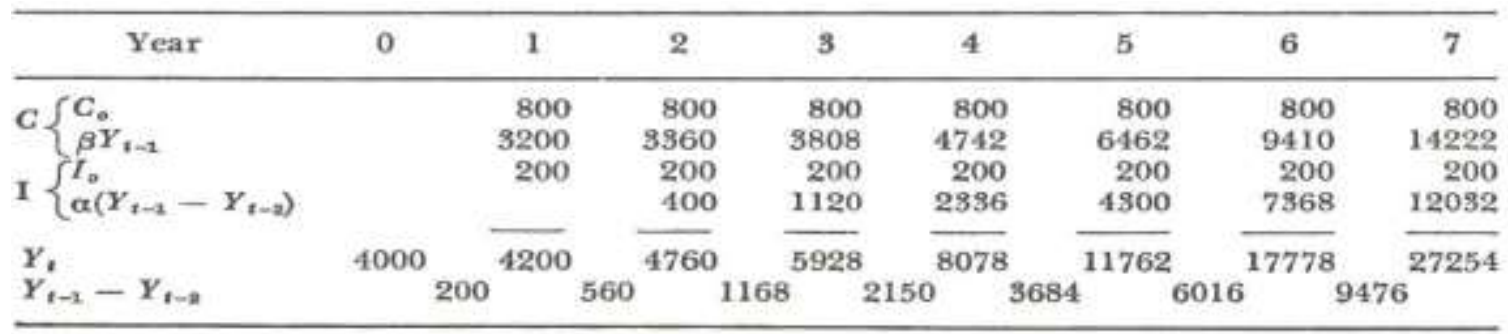


It can be seen that the income increases endlessly, when the accelerator also increases. These five cases are shown graphically in Figure 1.

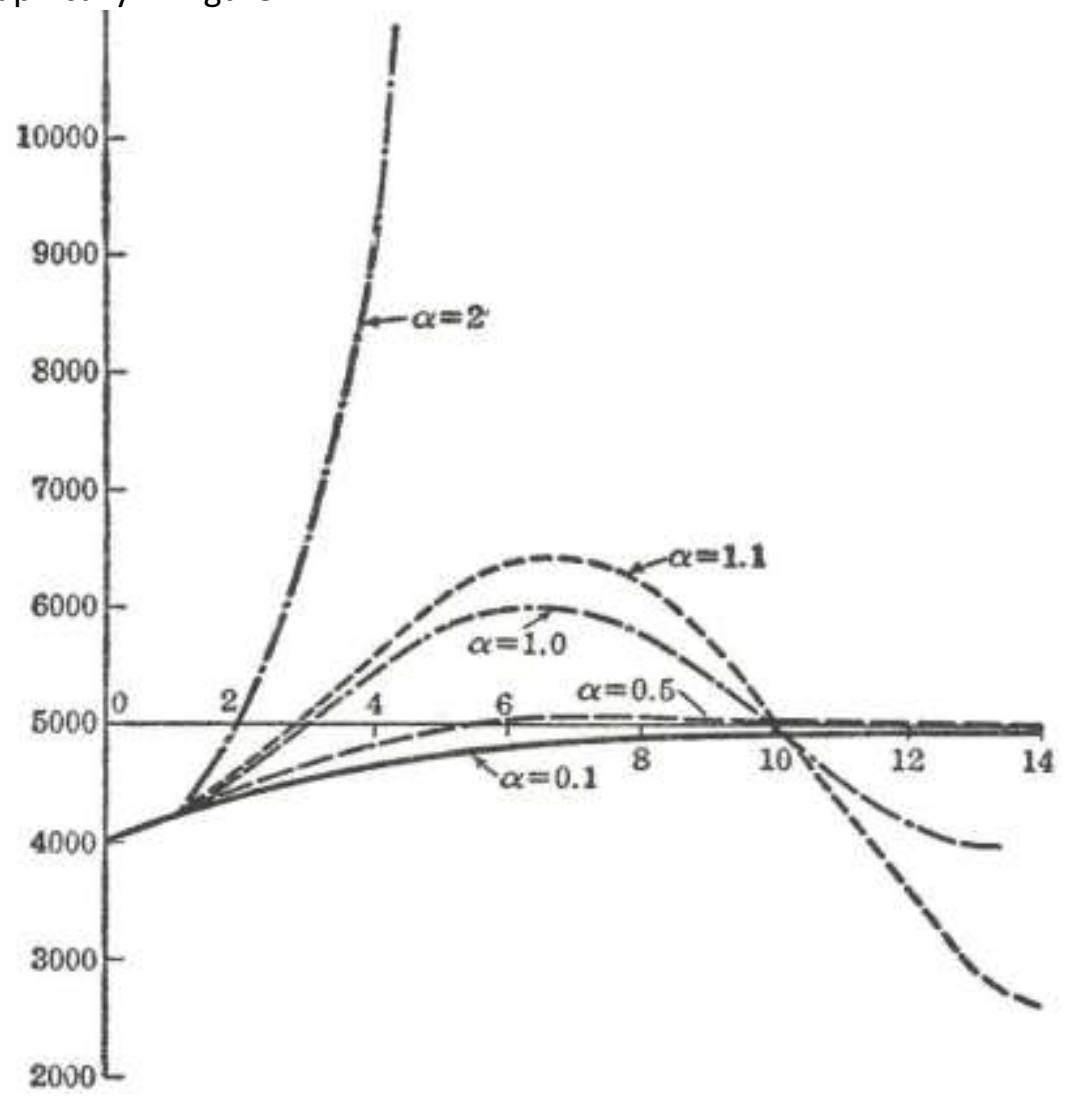

Figure 1. Different values of the accelerator

- The importance of the significance of the models

The economic significance of these dynamic systems is much lower than the purely mathematical analysis. It should be remembered first that the development of these models over time implies consistency with respect to the basic coefficients, the inclination towards consumption and the accelerator. This assumption is contradictory even in the case of inclination to consume.

The forecasts on the post-war national incomes of some countries, made in the years following the Second World War, were generally inconclusive, mainly because they were based on the values of the consumer function derived from the 1930s. 40, the consumption function had an upward change, for reasons that are more easily perceived after the event than before.

A small change in the level of the consumption function can create large changes in the equilibrium position, especially if the inclination to consume is close to 1.0. If the stability of the consumption function is controversial, there are many more contradictions regarding the stability of the accelerator. There is not much empirical evidence for the existence of an accelerator, let alone for its stability. Therefore, models that assume constancy through the accelerator should be used with caution and are not likely to be descriptive for current business cycles. The most reasonable aspect that such models can highlight is to suggest how cycles can be generated. If the cycles are generated in the indicated way, it means that they cannot be deduced from the theoretical models themselves.

\section{Conclusions}

The study that was the basis of this article gives the possibility to draw theoretical and practical conclusions. Thus, from a theoretical point of view, we find that a dynamic model must be accompanied by measures to ensure faster growth in order to ensure balance and macro-stability within an economy.

The presented models can be used individually or harmonized, taking into account that the problem is posed simultaneously to have a certain cycle of evolution to amortize "balance" the effects of the factors, 
to ensure a constant evolutionary cycle or to have a model in which we use an explosive cycle that allows the possibility of jumps to increase the result indicator that we consider.

Another conclusion is that this accelerator of dynamic models or dynamic models with accelerator is nothing but an interpretation of how the analysis leads to the need to permanently drive the evolution of the resultant variable.

\section{References}

1.Anghelache, C., Petre, A., Olteanu, C. (2019a), Some concepts and econometric models of macroeconomic performance analysis, Romanian Statistical Review, Supplement, no. 4, pp. 12-20.

2.Anghelache, C., Anghel, M. G., Marinescu, A. I. (2019b), The main indicators of national wealth that have an effect on macroeconomic performance, Romanian Statistical Review, Supplement, no. 3, pp. 14-2.

3.Anghelache, C., Anghel M. G. (2019a), Statistica economica generala, ediția a doua, revizuita și adaugita, Editura Economica, Bucureşti, 524 pp.

4.Anghelache, C., Anghel M. G. (2019b), Modelare economica. Teorie şi studii de caz, ediția a doua, revizuita și adaugita, Editura Economica, Bucureşti, 404 pp.

5.Anghelache, C., Anghelache, G. V., Barsan, O. (2019c), Modelul TRAMO - SEATS utilizat în analiza seriilor dinamice / The TRAMO - SEATS model used in the dynamic series analysis, Romanian Statistical Review, Supplement, no. 6, pp. 3-15 / 16-27

6. Barndorff-Neilsen, O., Hansen, P., Lunde, A., \& Shephard, N. (2008), Designing Realised Kernels to Measure the Ex-Post Variation of Equity Prices in the Presence of Noise, Econometrica 76, 1481-536.

7. Bollerslev, T., \& Wooldridge, J. M. (1992), Quasi-Maximum Likelihood Estimation and Interference in Dynamic Models with Time-Varying Covariances, Econometric Review 11, 143-72.

8. Linton, O. (2016), Probability, Statistic and Econometrics, Academic Press.

9. lacob, S. V. (2019), Utilizarea metodelor statistico-econometrice și econofizice în analize economice, Ed. Economica, $216 \mathrm{pp}$.

10. Scaillet, O. (2004), Nonparamertic Estimation and Sensitivity Analysis of Expected Shortfall, Mathematical Finance, 14, 115-29.

11. Stambaugh, R. F., \& Yuan, Y. (2017) Mispricing Factors, Review of Financial Studies 30, 1270-315. 